\title{
Article
}

\section{Assessing victim risk in cases of violent crime}

Khan, Roxanne, Willan, Victoria Jane, Lowe, Michelle, Robinson, Phaedra, Brooks, Matthew, Irving, May, Stokes, Rachel, GrahamKevan, Nicola, Karwacka, Marta and Bryce, Joanne

Available at http://clok.uclan.ac.uk/13410/

Khan, Roxanne ORCID: 0000-0002-3485-2450, Willan, Victoria Jane ORCID: 0000-0002-0023-7679, Lowe, Michelle ORCID: 0000-0001-9649-4938, Robinson, Phaedra, Brooks, Matthew ORCID: 0000-0002-5469-7769, Irving, May, Stokes, Rachel, Graham-Kevan, Nicola ORCID: 0000-0003-0621-3093, Karwacka, Marta et al (2015) Assessing victim risk in cases of violent crime. Safer Communities, 14 (4). pp. 203-211. ISSN 1757-8043

It is advisable to refer to the publisher's version if you intend to cite from the work. http://dx.doi.org/10.1108/SC-05-2015-0020

For more information about UCLan's research in this area go to http://www.uclan.ac.uk/researchgroups/ and search for <name of research Group>.

For information about Research generally at UCLan please go to

http://www.uclan.ac.uk/research/

All outputs in CLoK are protected by Intellectual Property Rights law, including Copyright law. Copyright, IPR and Moral Rights for the works on this site are retained by the individual authors and/or other copyright owners. Terms and conditions for use of this material are defined in the policies page.

\section{CLoK}

Central Lancashire online Knowledge www.clok.uclan.ac.uk

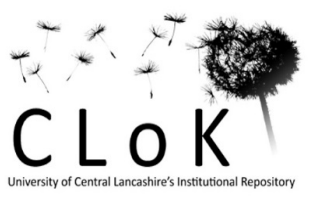




\section{Emerald Safer Communities}

\section{Assessing victim risk in cases of violent crime}

\begin{tabular}{|r|l|}
\hline Journal: & Safer Communities \\
\hline Manuscript ID: & Draft \\
\hline Manuscript Type: & Research Paper \\
\hline Keywords: & $\begin{array}{l}\text { Victims, Risk assessment, Domestic violence, Police, Victim Support, } \\
\text { MARACs }\end{array}$ \\
\hline \multicolumn{2}{|l}{} \\
\hline
\end{tabular}

\section{SCHOLARONE ${ }^{\text {m }}$ \\ Manuscripts}




\begin{abstract}
Purpose: There is a body of evidence that suggests a range of psychosocial characteristics demarcate certain adults to be at an elevated risk for victimisation. To this end, the aim of the current study was to examine consistency between one police force, and a corresponding victim support service based in England, in their assessment of level of risk faced by victims of violent crime.
\end{abstract}

Methodology: This study explored matched data on 869 adult victims of violent crime gathered from these two key services in Preston, namely Lancashire Constabulary and Victim Support, from which a sub-group of comparable 'domestic violence' cases $(n=211)$ were selected for further examination.

Findings: Data analyses revealed methodological inconsistencies in the assessment of victimisation resulting in discrepancies for recorded levels of risk in domestic violence cases across these two agencies.

Practical implications: These findings provide a compelling argument for developing a more uniformed approach to victim assessment and indicate a significant training need.

Value: This paper highlights areas of good practice and forwards several recommendations for improved practice that emphasises the integration of empirical research conducted by psychologists to boost the validity and reliability of risk assessment approaches and tools used.

Keywords: Victims; risk assessment; domestic violence; police, Victim Support, MARACs. 
Assessing victim risk in cases of violent crime

\section{Background}

Victims of violent crime experience a myriad of detrimental effects that can be both acute and chronic. Certain types of violent crime, such as domestic assault, are also strongly associated with increased risk of revictimisation (Turnanovic \& Pratt, 2014), the effects of which can be wider reaching than any immediate physical injury and can extend to psychological trauma presenting in low self-esteem, depression, self-harm, substance misuse, eating and sleeping disorders (Coker et al. 2002; Krug, Dahlberg, Mercy, Zwi \& Lozano, 2002). It is important therefore that any methods, tools or approaches used to assess victimisation are underpinned by empirical research that establishes the factors that place people at risk, thus enabling service providers to better safeguard the 'at risk' individuals who are brought to their attention. This process is also integral to the development of strategic, evidence-based, crime prevention, and reduction plans, which must also optimise and channel the often restricted funding available efficiently, with the ultimate aim of helping individuals who might be at an elevated risk of revictimisation.

Prevalence of revictimisation for violent crime

Examination of the Crime Survey England and Wales (CSEW) data during 2012-13 shows that at 26 percent, over one-quarter of all cases of violent crime were individuals experiencing revictimisation (Office for National Statistics, 2014). Indeed, over the last 15 national crime statistics surveys from 1981 to 2012/2013, the rates of revictimisation for all violent crime range as high as 23 percent (in 2008-09) to 38 percent (in 1995). It is noteworthy that the proportion of 'domestic violence' revictimisation cases, the most common form of repeat victimisation, has never fallen under one-third, peaked as high as 58 percent (in 1997) and averaged 45.53 percent over this period. Furthermore, under the 
Assessing victim risk in cases of violent crime

offence group of 'all violence', the proportion of revictimised individuals averaged at onefifth of the sample for 'wounding' (20.47\%) and one-quarter for 'injury' (24.47\%). These figures illustrate the detrimental consequences of violence that many victims have endured, whilst other studies paint a starker picture still, with adult violence revictimisation cases outweighing lone cases two-fold (see Lowe et al, under review). More pertinent to this paper however is an overview of the attempts made by different emergency and victim support agencies in the UK to assess victims' level of risk as this directly links in with any attempts to reduce the experience of victimisation.

\section{The evolution of victim risk assessment within the UK criminal justice system}

Motivated by the innovative work of forensic psychologists and academics in North America, the assessment and management of risk for reoffending has progressed significantly over the last 25 years. This work has advanced the methods in which risk of harmful behaviour is assessed by different criminal justice professionals across numerous offending populations. Currently, there are approximately 120 different structured instruments available to assess risk of different types of violence within a range of forensic and mental health settings in various countries (for an extensive review, see Singh \& Fazel, 2010). The need to evaluate the efficacy of these tools is underpinned by research that demonstrates varying degrees of predictive accuracy and validity (Singh, Grann, \& Fazel, 2011), and thus, a longstanding debate on the superiority of second-generation, actuarial measures of risk assessment over first-generation, clinically-based methods (Andrews \& Bonta, 2010) continues in light of contradictory evidence (Monahan \& Skeem, 2014; Skeem \& Monahan, 2011).

The innovative ripples of these seemingly robust and practical methods of risk assessment have seeped into frontline police work in the UK. Hoyle (2008) details how the Domestic Violence, Crime and Victims Act (2004), and its provision of new measures and 
powers for police caused an attitudinal shift resulting in officers demonstrating more willingness to engage with, and respond to domestic violence incidents. Significantly, common assault (i.e., a minor act of violence that does not cause an injury) was now an offence that could lead to arrest. Unsurprisingly, domestic violence-related arrests greatly increased in response to these changes, and consequently, the police were increasingly involved in the assessment of risk for domestic violence on the frontline - this meant a move for responding officers simply intervening at the scene of a potentially high risk altercation, towards evaluating the likelihood for future danger under unknown conditions (Hoyle, 2008). These changes are manifested in the development of Association of Chief Police Officers (ACPO) risk assessment (2008) guidelines, that recommend the use of risk assessment tools (in which risk factors for both perpetrators $(n=10)$ and victims $(n=5)$ are highlighted), to support officers in the identification of high-risk domestic violence victims.

A more recent UK police-based development, born out of the SPECSS + tool [1], is the DASH [2] (2009). This is a triadic-structured risk assessment list for use by police officers in response to incidents of domestic violence at the following stages: (1) initial assessment at scene of incident; (2) interventions by dedicated officer, and (3) risk management planning (Richards, Letchford, \& Stratton, 2008). Hoyle (2008) notes that risk assessment instruments in the UK focus on victims' information and perceptions, thus placing emphasis on them to account for the offender's behaviour and overlooking all other risks. Conversely, North American tools use information collected from several sources, weighted towards reports about the perpetrator from both professional sources and the offender themselves.

A similar approach underlies local level multi-agency risk assessment conferences (MARACs) in England and Wales; these sessions allow a number of relevant professional agencies (e.g. police and independent victim support agencies) to manage 'high risk' 
Assessing victim risk in cases of violent crime

domestic violence victims using a tool developed by Coordinated Action Against Domestic Abuse (CAADA, 2012), the DASH-MARAC Risk Identification Checklist (Robbins, McLaughlin, Banks, Bellamy \& Thackray, 2014). The principle underlying the use of these tools is that they "provide a structured way for responding officers to gather detailed and relevant information from victims. This information, particularly when shared with other agencies, can help provide better service to victims because their specific needs are identified" (Robinson, 2004, p .8). However, despite approximately 250 MARACs in operation, recent reports suggest the evidence for their efficacy in reducing repeat victimisation might be untenable (see Steel, Blakeborough \& Nicholas, 2011), thus providing a rationale for conducting the present study which aims to comparatively evaluate the levels of victimisation risk as ascertained by emergency and victim support services.

Aim of the current study: This investigation involved examining how victims' level of risk was assessed across two pivotal services (namely, Lancashire Constabulary and Victim Support) located in Preston City, based in North West England, with aim of gauging potential reliability and validity issues in the methods used. There is clear value in conducting a comparative analysis of victimisation risk levels, as this has ramifications for the selection of 'high risk' cases forwarded for review at MARACs.

The 2011 census reports Preston City's population as 140, 202, with an approximately equal gender-split. The average age was 37 years with a low median age of 35 possibly reflecting the student population in this expanding university town; Preston's university student population at above 32,000 is the eighth largest in the UK in terms of student numbers (HESA Statistics, Higher Education numbers 2008/2009). Preston is an ethnically diverse city, and aside from the indigenous White British (79.8\%) population, the largest minority ethnic groups recorded were those from a South Asian heritage (7\%). Lancashire Constabulary is the police force responsible for Preston; at the time of this study, the force 
Assessing victim risk in cases of violent crime

had six geographical divisions and two specialist divisions. Since April 2014, Lancashire

Constabulary has been restructured into three Basic Command Units (BCUs) and Preston

City is now part of 'South BCU'. The police force puts victims of crime in contact with

Victim Support [3], who, as an independent charity organisation can provide free confidential support, practical help and information to support crime victims and, according to their website, provides this service to more than 8,000 victims in Lancashire annually. All aspects of the study complied with institutional and British Psychological Society (BPS) ethical guidelines, and strict protocols were followed to ensure that it was not possible to identify individuals from the information provided in the datasets used for analysis.

\section{Method}

\section{Sampling and Measures}

Initially, a comprehensive dataset was created by extracting information on victims of all adult violent crime recorded during a six-month period (April 2013-September 2013) held by (i) Lancashire Constabulary ( $\mathrm{n}=1227)$, and (ii) Victim Support $(\mathrm{n}=1219)$ both based in Preston in Lancashire for the postcode PR1 and PR2. Using crime reference numbers, a total of 869 cases were then anonymously matched across the two archives, providing demographic data relating to the victims' age, gender, and ethnicity. Information pertaining to how the victims were classified by both agencies, in relation to (a) crime-classification plus their (b) level of risk, was also entered into the final dataset for statistical analysis using SPSS v.21.

\section{Results}

Descriptive statistics: Varying types of crime victimisation were reported by the diverse group of adults in this sample. An examination of the demographic data revealed that 
Assessing victim risk in cases of violent crime

victims' ages were widely dispersed (range $=16$ to 90 years; mean=32.51 years, $\mathrm{SD}=12.62$, mode $=21.00)$ with no discernible gender differences (males $=456$; females $=413)$. A breakdown of victims' ethnicity showed that while a majority were White European $(n=664$; $76.4 \%)$, nearly a fifth of this sample were of South Asian origin $(n=153 ; 17.6 \%)$. A similar number of victims in this sample were Black $(n=17 ; 2.0 \%)$ or of a Mixed background $(n=16$; $1.8 \%$ ) although some information on ethnicity was not provided as several cases were recorded as 'unknown' $(\mathrm{n}=19 ; 2.2 \%)$. The types of crime victimisation recorded for this population were classified differently by both agencies. To allow for consistent analysis across these two agencies, the crime-type categories were recoded and reduced into four categories as shown in Table 1.

Insert Table 1 here

Given the diversity of offences recorded and an unascertainable range of methods most likely used across the two agencies to assess risk in relation to type of crime, it was decided, in order to extrapolate comparable data, to focus only on cases that could be classified as 'domestic violence'; the rationale for this is based on the use of DASH-based tools by both Lancashire Constabulary and Victim Support to evaluate such cases - focusing on a specific offence-classification and related level of risk as ascertained by using a similar assessment tool would allow for more meaningful results. Thus, the remaining analyses focused solely on a matched sub-group of domestic violence cases $(n=211)$ as recorded by both Lancashire Constabulary and Victim Support. 
Assessing victim risk in cases of violent crime

A demographic breakdown of just these domestic violence cases revealed a majority of these victims were females $(n=189 ; 89.6 \%)$ whose ages were widely dispersed (range=1668 years; mean $=31.93 ; 11.47 ;$ mode $=21.00 ;$ median $=30.00)$. Unlike the ethnic composition of victims for all recorded crime, there was very little diversity in ethnic background in this sub-group of domestic violence cases; a majority of victims were of White European descent $(n=190,90.0 \%)$, followed by a small proportion of victims recorded from a South Asian $(n=17,8.1 \%)$, Mixed $(n=3,1.4 \%)$, and Black $(n=1,0.5 \%)$ origin. Next, these matched domestic violence cases and their associated 'levels of risk' as recorded by Lancashire Constabulary and Victim Support were examined separately to allow for comparative analysis, as summarised in Table 2.

Insert Table 2 here

Inferential statistics: These data were analysed using Chi-square tests as this enabled an examination of any significant differences between the expected frequencies and the observed frequencies in one or more of the recorded categories of 'unknown', 'low', 'medium', or 'high' for these domestic violence cases. Indeed, 'level of risk' recorded across the two databases held by Lancashire Constabulary and Victim Support was significant (X2 $(3)=142.63, p<.001)$. Therefore, there is statistical evidence to suggest that either of these two service providers and their recording of victim's level of risk are not independent of each other and thus, there is an association between level of risk and type of service. More specifically, Lancashire Constabulary were likely to classify victims' level of risk as 'medium', and a slight tendency to assign 'unknown', more than expected. Whereas Victim Support were less likely to classify victims' level of risk as 'unknown' or 'medium', and 
Assessing victim risk in cases of violent crime

much more likely to classify victims' level of risk as 'low' or 'high'. To this end, the evidence suggests that Lancashire Constabulary typically classify domestic violence victims' level of risk as 'medium', whilst Victim Support are more likely to record these victims' level of risk as either 'low' or 'high'.

The effects of victim demographics of age, gender and ethnicity on risk levels for domestic violence were also explored further, for Lancashire Constabulary and Victim Support separately. For Lancashire Constabulary, the relationship between assigned risk levels with age (Spearman's rho $=-.01, \mathrm{p}=.939)$, and gender $(\mathrm{X} 2(3)=5.65, \mathrm{p}=.130)$ were non-significant. With respect to ethnicity, a Kruskall-Wallis H test also identified a nonsignificant difference in risk level between ethnic groups $(\mathrm{X} 2[3]=3.93, \mathrm{p}=.349)$ : However, it was clear that South Asian victims were ranked at a lower risk (mean rank $=81.71$ ) than other ethnicities; Black (mean rank $=122.50)$, Mixed (mean rank $=112.00)$; White (mean rank $=107.99)$.

For Victim Support risk levels, whilst age was unrelated to risk level (Spearman's rho $=.13, \mathrm{p}=.057)$, a marginally significant 2 (gender) $\mathrm{x} 4$ (risk level) Chi-square was documented $(\mathrm{X} 2(3)=7.73, \mathrm{p}=.051)$. An inspection of the expected and observed frequencies for each cell (see Table 2) showed that more males were classed as 'unknown' than expected, whereas more females' ratings across the classification levels were as expected. With respect to ethnicity, a Kruskall-Wallis H test identified a non-significant difference in risk level between ethnic groups $(\mathrm{X} 2[3]=2.37, \mathrm{p}=.499)$.

\section{Discussion}

Despite the efforts of emergency and support services to safeguard those at elevated risk of victimisation, this study revealed discrepancies in the ascribed levels of risk across these two key agencies. For example, Lancashire Constabulary were more likely to code 
victims' level of risk as 'medium', compared with Victim Support, who were more likely to classify victims as 'low' or 'high' risk. It is also noteworthy that the police classified just under one-quarter of this domestic violence sample (23.7\%) as having an 'unknown' level of risk, in comparison to Victim Support, who only coded a small number of these victims under that classification (6.6\%). Also, Victim Support classified twice as many cases as 'high risk' $(43.6 \%)$ than did Lancashire Constabulary $(22.3 \%)$, which has serious and worrying implications for the police's selection of domestic violence cases to be forwarded for review at MARACs, especially, as Steel et al. (2011) note, most cases reviewed at these interagency forums are referred by the police.

Further analysis was restricted due to limited data but it would be interesting to examine whether these discrepancies were situationally-related to when the assessment information was collected from the victim; that is, if assessments were usually made by responding officers during potentially volatile situations at the scene of an offence, or in a more counselling-based setting typically made by Victim Support, at any period after the offence has taken place. Alternatively, this variance could reflect the different levels of training received by emergency versus victim support services, or even a manifestation of a workplace ethos and role expectations. For instance, unlike police officers (whose roles cover law, order and protection and are consequently more diverse), Victim Support workers more typically engage with vulnerable victims on a one-to-one basis, and are expected to respond in a sensitive and receptive manner to disclosures of abuse, and thus, they may be more attentive or confident in assigning a higher risk classification to domestic violence victims.

Only one significant difference in classifications of risk was evident across the two services in relation to victim demographics. Notably, Lancashire Constabulary more typically classified male victims' risk level as 'unknown' than any other risk level in comparison to their classification of female victims. As Bowen (2011) notes, raised awareness of male 
Assessing victim risk in cases of violent crime

domestic violence victimisation in the empirical literature is not yet matched in the development of appropriate victimisation practitioner guidelines. It was also clear from examining the descriptive statistics that South Asian victims of domestic violence were classified to be at a lower risk compared to all other ethnic groups by the police. Although purely speculative, it would be useful to examine whether the police's reported use of the ACPO-DASH (which has ten additional 'honour'-based violence (HBV) items) and Victim Support's stated use of the CAADA-DASH (which does not have any HBV items), has any bearing on this outcome, but as no information on this is recorded in the databases, this avenue could not be explored further.

It is important to highlight that whilst the use of a published instrument such as the DASH demonstrates an attempt to improve consistency across agencies, there are a number of problems that emerge from this such tools. For example it has not been possible to locate any independent evaluations of the DASH. The one exception is a Master's project study conducted by Edwards (2011) however, this is not publically accessible. Thus, any confidence held in the reliability of this assessment tool cannot be rooted in its empiricalstrength because this instrument's validity and efficacy has not been systematically tested or published to date. It is probably prudent to take heed of Stanley and Humphreys' (2014, p. 81 ) words that " $[\mathrm{P}]$ roblems can occur if tools confer an illusion of science and objectivity that is deceptive". Further, there are a number of different versions of the DASH available for use [4], despite no assurances that practitioners who use this tool are choosing the correct version or have sufficient training or indeed, any confidence in completing the assessment reliably. In a critical review of the UK police's use of victim assessment models, Hoyle (2008, p. 330) argued that caution should be applied because “... risk assessment models for domestic violence are not as scientifically rigorous as those using them might presume". 
Assessing victim risk in cases of violent crime

From an academic perspective, there are several explanations in the psychological literature to explain why these differences might occur as a result of judgment heuristics, social bias and the influence of fundamental attribution errors (Bowen 2011; Elbogen, 2002; Smith \& Alpert, 2007; Stroshine, Alpert, \& Dunham, 2008). This empirical evidence ought to guide the design of risk assessment instruments and the method in which they are administered, because it is evident that the inconsistent levels of risk across these two services, to some degree, reflect a difference in the administration of victim assessment. This suggests a significant training-need to improve assessment reliability and cross-agency consistency. Practitioner training is a repeatedly recognised element of improving the efficacy of victim assessment (Ruff, 2012). Indeed, Humphreys et al (2005) ascertained, as a result of their research with Metropolitan Police and West Yorkshire Police, that just under half of the officers in their sample were not sufficiently trained to use risk assessments in line with ACPO guidelines. It is also apparent that more efforts could be made to bridge the gap between the significant advancements in academic theory regarding what works best in the practice of risk assessment so that it better aligns with the delivery of frontline service provision for victims. It is perhaps not surprising however that practitioners might struggle to maintain the same pace as academic productivity, given the sheer volume and complexity of research published on risk assessment during the last two decades.

Several areas of good practice were established in this study. For example, it was notable that Lancashire Constabulary and Victim Support demonstrated a willingness to collaborate with independent researchers to investigate issues related to victim assessment in an attempt to improve applied practice. Due to the heterogeneity of victim-demographics from one postcode, community or even region to the next, it is profitable to identify trends for violence victimisation according to specific populations according to locality. Thus, a local academic research team (from the University of Central Lancashire, Preston Campus) working in 
alliance with local police and victim support services promotes a positive message about multiagency collaborations, and a desire for independent evaluations for improved practice by all parties. There is scope for similar local collaborations nationwide. Additionally, attempts made by Lancashire Constabulary and Victim Support to use a 'common tool' (e.g. DASH-based instruments) to identify high risk cases of domestic violence for MARACs demonstrates attempts to improve consistency across agencies.

Nonetheless, when efforts are made to use such 'common tools', it is unclear at which point in time the assessment is made by different agencies, which version of the instrument is used, and the level of training across the different agencies. To some extent, this might explain the differences found between Lancashire Constabulary and Victim Support and their levels of risk recorded for victims. These results make clear that there is an aspiration, and ample room, to improve the reliability and validity of the measures used. However, it is somewhat paradoxical that in an attempt to improve consistency across agencies for victim risk assessment, practice guidelines encourage the use of potentially unreliable, non-validated measures for both Lancashire Constabulary and Victim Support. To this end, these findings support any efforts to independently evaluate the DASH (all versions) for both reliability and validity for use with the specific populations and offences they are designed for (for example, 'honour'-based violence, or stalking, etc.). It would be desirable for any evaluations to be conducted by independent researchers who have a solid understanding of the methodological principles underlying risk assessment in practice settings, working collaboratively with police and victim support service workers. The development and administration of the B-SAFER (Brief Spousal Assault Form for the Evaluation of Risk: Kropp, Hart, \& Belfrage, 2005) serves as a worthy example of good practice; is a well-validated instrument designed to assist practitioners in case management. This tool does not employ statistical methods on which to 
Assessing victim risk in cases of violent crime

base evaluations of risk, but instead provides guidelines for gathering relevant information and making structured and informed decisions.

\section{Conclusions}

A plethora of research emphasises that risk assessments must always be conducted with great caution. Fundamentally, that practitioners must be fully attuned to the principles underlying any tool chosen in order to have confidence in its validity and reliability. Rogers (2000), whose critique of approaches to risk assessment was published over a decade ago, highlights important issues that are much a concern today as when the paper was first published. He states that his ... "commentary on risk assessment is not intended as a wholesale indictment. Rather, its purpose is to temper the unbridled enthusiasm by articulating the perils and pitfalls regarding any uncritical acceptance of risk assessment" (p. 595). To this end, the main crux of this study's findings is that practitioners should not be tempted to use risk assessment tools simply because they are readily available, and more attention must be given to bridging the vast gap between theory and practice, to better align the ever growing empirical evidence with the complexities of work with vulnerable victims on the frontline.

\section{References}

Association of Chief Police Officers (ACPO). (2008). Guidance on investigating domestic violence. London: NPIA.

Andrews, D. A., \& Bonta, J. (2010). The psychology of criminal conduct. Elsevier.

Bowen, E. (2011). An overview of partner violence risk assessment and the potential role of female victim risk appraisals. Aggression and Violent Behavior, 16(3), 214-226. 
Assessing victim risk in cases of violent crime

Coker, A. L., Davis, K. E., Arias, I., Desai, S., Sanderson, M., Brandt, H. M., \& Smith, P. H. (2002). Physical and mental health effects of intimate partner violence for men and women. American Journal of Preventive Medicine, 23(4), 260-268.

Douglas, K. S., Cox, D. N., \& Webster, C. D. (1999). Violence risk assessment: Science and practice. Legal and Criminological Psychology, 4(2), 149-184.

Elbogen, E. B. (2002). The process of violence risk assessment: A review of descriptive research. Aggression and Violent Behavior, 7(6), 591-604.

Edwards, C. (2011) Preventative not predictive: the DASH (2009) risk identification, assessment and management model. MSc dissertation, University of Portsmouth.

Evans, C., Mellor-Clark, J., Margison, F., Barkham, M., Audin, K., Connell, J., McGrath, G. (2000). CORE: Clinical outcomes in routine evaluation. Journal of Mental Health, 9(3), 247-255.

Gray, J. (2001). The framework for the assessment of children in need and their families. Child Psychology and Psychiatry Review, 6, 4-10.

HESA Statistics - Higher Education numbers 2008/2009) (Excel). Higher Education Statistics Agency.

Hoyle, C. (2008). Will she be safe? A critical analysis of risk assessment in domestic violence cases. Children and Youth Services Review, 30(3), 323-337.

Humphreys, C., Thiara, R. K., Regan, L., Lovett, J., Kennedy, L., \& Gibson, A. (2005). Prevention not prediction. A preliminary evaluation of the Metropolitan Police Domestic Violence Risk Assessment Model (SPECSS), Final Report, University of Warwick/Centre 
Assessing victim risk in cases of violent crime

for the Study of Safety and Wellbeing, London Metropolitan University/Child and Women Abuse Studies Unit.

Krug, E. G., Mercy, J. A., Dahlberg, L. L., \& Zwi, A. B. (2002). The world report on violence and health. The Lancet, 360(9339), 1083-1088.

Lowe, M., Willan, V., Graham-Kevan, N., Brooks, M., Irving, M., Karwacka, M., . . Bryce, J. (under Editorial review). Investigating repeated victimisation in a UK police sample of adult victims of violent crime. Policing \& Society.

Monahan, J., \& Skeem, J. L. (2014). The evolution of violence risk assessment. CNS Spectrums, 1-6.

Office for National Statistics. (13 February 2014). Chapter 1 - overview of violent crime and sexual offences 2012/13. C Crown Copyright.

Office for National Statistics. (28 November 2013). Chapter 2 - repeat victimisation. (C) Crown Copyright.

Richard, R. (2000). The uncritical acceptance of risk assessment in forensic practice. Law and Human Behavior, 24(5), 595-605.

Richards, L., Letchford, S., \& Stratton, S. (2008). Policing domestic violence. Oxford University Press.

Robbins, R., McLaughlin, H., Banks, C., Bellamy, C., Thackray, D., \& Penhale, B. (2014). Domestic violence and multi-agency risk assessment conferences (MARACs): A scoping review. The Journal of Adult Protection, 16(6), 389 -398. 
Assessing victim risk in cases of violent crime

Robinson, A. L. (2004). Domestic violence MARACS (multi-agency risk assessment conferences) for very high-risk victims in Cardiff, Wales: A process and outcome evaluation. Cardiff: University of Cardiff,

Ruff, L. (2012). Does training matter? Exploring police officer response to domestic dispute calls before and after training on intimate partner violence. The Police Journal, 85(4), 285-300. doi:10.1350/pojo.2012.85.4.516

Singh, J. P., \& Fazel, S. (2010). Forensic risk assessment: A meta review. Criminal Justice and Behavior, 37(9), 965-988.

Singh, J. P., Grann, M., \& Fazel, S. (2011). A comparative study of violence risk assessment tools: A systematic review and meta regression analysis of 68 studies involving 25,980 participants. Clinical Psychology Review, 31(3), 499-513.

Skeem, J. L., \& Monahan, J. (2011). Current directions in violence risk assessment. Current Directions in Psychological Science, 20(1), 38-42.

Smith, M. R., \& Alpert, G. P. (2007). Explaining police bias: A theory of social conditioning and illusory correlation. Criminal Justice and Behavior, 34(10), 1262-1283.

Stanley, N., \& Humphreys, C. (2014). Multi-agency risk assessment and management for children and families experiencing domestic violence. Children and Youth Services Review, 47, 78-85.

Steel, N., Blakeborough, L., \& Nicholas, S. (2011). Supporting high-risk victims of domestic violence: A review of multi-agency risk assessment conferences (MARACs). (No. Research Report 55 Summary). London: Home Office. 
Assessing victim risk in cases of violent crime

Stroshine, M., Alpert, G., \& Dunham, R. (2008). The influence of “working rules” on police suspicion and discretionary decision making. Police Quarterly, 11(3), 315-337.

Turanovic, J. J., \& Pratt, T. C. (2014). “Can’t stop, Won’t stop”: Self-control, risky lifestyles, and repeat victimization. Journal of Quantitative Criminology, 30(1), 29-56.

Weisz, A. N., Tolman, R. M., \& Saunders, D. G. (2000). Assessing the risk of severe domestic violence the importance of survivors' predictions. Journal of Interpersonal Violence, 15(1), 75-90.

[1] An acronym an earlier risk assessment model used by the police built on the following six high risk factors: Separation; Pregnancy/new birth, Escalation, Cultural issues/sensitivity, Stalking, Sexual assault.

[2] DASH is an acronym used for 'Domestic Abuse, Stalking and 'Honour'-based Violence'.

[3] The 'Victims Code of Practice' (2006) obliges the police to report all recorded crime to Victim Support, via a broad policy of automatic referral of victims'. This process has been adopted by ACPO, supported by the National Office of Victim Support and the Data Protection Registrar.

[4] For example, DASH (Richards, 2009). S-DASH (Sheridan, Roberts, \& Richards, 2009), V-DASH (Richards, 2010), CAADA-DASH RIC (CAADA, 2012), ACPO-DASH (version 2014). 
Assessing victim risk in cases of violent crime

2

Table 1: Five new recoded crime categories using matched cases $(n=869)$ from Lancashire Constabulary and Victim Support.

\begin{tabular}{|l|l|l|}
\hline & $\begin{array}{c}\text { Lancashire Constabulary } \\
\text { Frequency and (\%) }\end{array}$ & $\begin{array}{c}\text { Victim Support } \\
\text { Frequency and (\%) }\end{array}$ \\
\hline Threat and Physical Assault: Minor & $262(30.1 \%)$ & $298(34.3 \%)$ \\
\hline Threat and Physical Assault: Major & $405(46.5 \%)$ & $181(20.8 \%)$ \\
\hline Harassment and Hate Crimes & $149(17.1 \%)$ & $179(20.6 \%)$ \\
\hline Robbery & $52(6.0 \%)$ & $44(5.1 \%)$. \\
\hline
\end{tabular}


Assessing victim risk in cases of violent crime

Table 2: Level of risk recorded by Lancashire Constabulary and Victim Support for a matched sub-group of domestic violence cases $(n=211)$ : overall and in relation to gender.

\begin{tabular}{|l|l|l|l|l|l|l|}
\hline Level of risk & \multicolumn{3}{|c|}{$\begin{array}{c}\text { Lancashire Constabulary } \\
\text { Frequency and (\%) }\end{array}$} & \multicolumn{3}{c|}{ Fictim Support } \\
& \multicolumn{3}{|c|}{ Frequency and (\%) } \\
\hline & Male & Female & Total* & Male & Female & Total* \\
\hline Unknown & $9(40.9 \%)$ & $41(21.7 \%)$ & $\mathbf{5 0 ( 2 3 . 7 \% )}$ & $3(13.6 \%)$ & $11(5.8 \%)$ & $\mathbf{1 4}(6.6 \%)$ \\
\hline Low & $4(18.2 \%)$ & $26(13.8 \%)$ & $\mathbf{3 0}(\mathbf{1 4 . 2 \% )}$ & $7(31.8 \%)$ & $93(49.2 \%)$ & $\mathbf{1 0 0}(47.4 \%)$ \\
\hline Medium & $7(31.8 \%)$ & $77(40.7 \%)$ & $\mathbf{8 4}(39.8 \%)$ & $2(9.1 \%)$ & $3(1.6 \%)$ & $\mathbf{5 ( 2 . 4 \% )}$ \\
\hline High & $2(9.1 \%)$ & $45(23.8 \%)$ & $\mathbf{4 7 ( 2 2 . 3 \% )}$ & $10(45.5 \%)$ & $82(43.3 \%)$ & $\mathbf{9 2 ( 4 3 . 6 \% )}$ \\
\hline
\end{tabular}

* Total refer to percentages for the sample overall 